\title{
Этическая компонента стратегических коммуникаций в медиатизированном обществе
}

\author{
Владимир Горохов \\ Вероника Простякова
}

\begin{abstract}
Авторы рассматривают развитие стратегических коммуникаций в медиатизированном обществе и анализируют один из важнейших, но малоизученных аспектов деятельности стратегических коммуникаций этику. В современном технологически развитом медиатизированном обществе этика стратегических коммуникаций приобретает все большее значение не только для профессиональных коммуникаторов, но и для целевой аудитории. Этика в данном случае выступает как фактор взаимоотношений организации с заинтересованными сторонами в ходе стратегических коммуникаций.
\end{abstract}

Ключевые слова: стратегические коммуникации, медиатизированное общество, этика.

DOI: 10.30547/mediaalmanah.5.2020.3641

(C) Горохов Владимир Маркович доктор филологических наук, профессор кафедры рекламы и связей с общественностью факультета журналистики МГУ имени М.В. Ломоносова (г. Москва, Россия), reklama202@mail.ru

(c) Простякова Вероника Алексеевна младший научный сотрудник кафедры рекламы и связей с общественностью факультета журналистики МГУ имени М.В. Ломоносова (г. Москва, Россия), vprostyakova@mail.ru
Трансформация моделей коммуникации в современном обществе повлекла за собой структурные преобразования в общественной сфере, особенно в развитии социальных медиа, которые влияют на формирование общественного мнения. По данным опроca European Communication Monitor о важности различных каналов и инструментов коммуникации (Zerfass, Verhoeven, Moreno, Tench et al., 2020), предпочтение социальным сетям отдали $87 \%$ респондентов, на втором месте - онлайн-общение, электронная почта и Интранет, межличностное общение $(82,1 \%)$, далее следуют распространение новостей через онлайн-СМИ $(80,0 \%)$ и мобильное общение через приложения для телефонов и планшетов, мобильные сайты (75,3\%). Авторы исследования отметили, что социальные сети показали явный рост (от 10\% в 2007 г. до почти $90 \%$ в 2020 г.), в то время как использование традиционных СМИ в качестве посредников коммуникации существенно сокращается. Не менее значительная роль отводится стратегическим коммуникациям в современном медиатизированном обществе, а трансформация моделей коммуникации в сочетании с профессиональными компетенциями коммуникаторов качественно изменили информационную среду.

Изучению стратегических коммуникаций посвящены работы как отечественных, так 
и зарубежных исследователей: московская академическая школа представлена работами Е.Л. Вартановой (2019), В.М. Горохова, М.Г. Шилиной (2019); Т.Э. Гринберг (2018), В.М. Горохова, М.Г. Шилиной, С.А. Вартанова (2019), Н.В. Старых (2013); среди зарубежных исследователей коммуникаций заслуживают внимания работы: К. Хэллахана, Д. Хольцхаузен, Б. ван Рулер, Д. Верчича (2007), Д. Хольцхаузен, А. Зерфасса (2015), Дж. Грунинга (2006), А. Хеппа (2020). Этическому аспекту коммуникаций посвящены работы Р. Пирсона (1989), Ш. Боуэн (2004, 2005, 2006, 2016).

\section{Стратегические коммуникации в медиатизированном обществе}

Стратегические коммуникации - непременное условие формирования миссии организации. До недавнего времени стратегическая коммуникация рассматривалась либо как универсальный термин, используемый в различных контекстах, либо как точечный фрагмент анализа. С одной стороны, это понятие было синонимом всех типов целенаправленной коммуникации, включая, например, маркетинговые коммуникации. С другой стороны, термин использовался национальными и международными организациями для продвижения своих интересов.

С середины 2000 гг. концепция стратегической коммуникации становится все более популярной как среди практиков, так и среди ученых. Сегодня практики часто используют этот термин, говоря о долговременной программе развития организации, а исследователи применяют этот термин как исторический принцип изучения коммуникативных практик. Можно выделить несколько подходов к концепции стратегических коммуникаций: 1) это популярный академический термин, поддающийся различным интерпретациям, не имеющий единообразного толкования; 2) это новая парадигма или особый подход анализа (Holtzhausen, Zerfass, 2015: 4), который открывает возможности для проведения междисциплинарных исследований. К. Хэллахан, Д. Хольцхаузен, Б. ван Рулер, Д. Верчич (2007) подчеркивают, насколько важно учитывать концептуальные представления о коммуникативных процессах и эффектах: например, трансмиссионная и интерактивная модели коммуникации также рассматривались в качестве актуальных моделей стратегических коммуникаций. Сегодня гораздо больше внимания уделяется конститутивной модели коммуникации, а также символическому интеракционизму и постмодернизму как теоретической основе этой модели. Коммуникативную деятельность организации лучше всего рассматривать с интегративной точки зрения. Однако стратегическая коммуникация отличается от, например, интегрированной маркетинговой коммуникации тем, что сосредоточена на коммуникационной деятельности в различных областях коммуникаций. В этой связи ключевая роль стратегической коммуникации отводится публичной сфере или коммуникативной сфере, которая стала скорее партисипативной, чем репрезентативной (Bentele, Nothhaft, 2010: 96). Следовательно, внешнее проявление стратегической коммуникации (например, поддержание благоприятной репутации) становится более приоритетным.

Стратегические коммуникации влияют на формирование общественного мнения и конструирование реальности в медиатизированных обществах в огромной степени (Hepp, 2020; Knoblauch, 2020). Наблюдаемым индикатором существования медиатизированного общества является повсеместная медиатизация социальных институтов, то есть представительство этих институтов в реальном и виртуальном коммуникационном пространстве.

Выделим основные признаки медиатизированного общества:

- масштабность явления, когда включенность в медиаотношения становится 
необходимым условием социальной активности всех слоев населения;

- предметная универсальность: медиаструктуры присутствуют в экономике, политике, культуре и т.д.;

- полисубъектность медиа: совокупность институциональных и неинституциональных субъектов информационной деятельности, воспроизводящих всю гамму интересов в обществе;

- адекватная информационно-технологическая платформа, представляющая мультимедийные, интерактивные ресурсы для достижения тактических и стратегических целей членов общества;

- целеполагающая доминанта публичного гражданского диалога, когда на форуме или в блоге представляется частная информация - это только периферийная сторона медиаотношений, не претендующая, как правило, на общезначимую реакцию;

- переструктурирование традиционных средств массовой и корпоративной информации, преобразующих себя в условиях соревнования с альтернативными источниками информации;

- умножение (благодаря коммуникационным медиаотношениям, которые становятся производительной силой) потенциала личности, группы,социума и создание кумулятивного социального эффекта;

- глобализация медиаконтактов, обеспечивающих транзит информации, преодолевающих региональную замкнутость и создающих транснациональную информационную среду;

- трансформация структуры общества, когда социальные страты образуются на основе коммуникационных предпочтений, а профессиональные компетенции согласуются с медийной квалификацией;

- и, наконец, главное: медиатизированное общество восходит к новому качеству жизнедеятельности человека, когда доминирующие позитивные результаты сочетаются с появлением новых проблем и противоречий с серьезными, часто непрогнозируемыми вызовами, требующими сосредоточения концептуальных усилий специалистов всего сектора научного знания (Горохов, 2018: 8).

Таким образом, медиатизированное общество характеризуется универсальной совокупностью институциональных и неиституциональных субъектов информационной деятельности, реализующих свои интересы в публичном коммуникационном пространстве. Медийные отношения становятся фактором социальной стратификации, производительной силой, умножающей потенциал личности, группы, социума и порождающей кумулятивный эффект коммуникационных процессов. Медиатизированное общество - закономерный этап цивилизационного развития, обусловленный информационно-технологическими ресурсами нового поколения и коммуникационной проекцией на все сферы публичной деятельности, в том числе и на сферу этики.

\section{Роль этики в стратегических коммуникациях}

С 2007 г. Европейская ассоциация по связям с общественностью, образованию и исследованиям (EUPRERA) ежегодно проводит международный опрос European Communication Monitor, в котором участвуют более 2000 респондентов - практикующих специалистов в области стратегических коммуникаций из 40 европейских стран. В 2020 г. одной из тем исследования стала этика. Так, согласно данным опроса, 76,5\% респондентов руководствовались этическими принципами, разработанными собственной организацией, большинство (86,1\%) использовали личные ценности и убеждения (например, основанные на семейных традициях, образовании или религии). Большая часть респондентов сталкиваются с этическими проблемами: например, 67,6\% заявили, что использовать боты для создания обратной связи в социальных сетях очень сложно с этической точки зрения. Эти данные указывают на то, 
что этические принципы в области коммуникаций либо малоизвестны, либо им уделяется недостаточно внимания.

Цифровые технологии предлагают множество возможностей для развития стратегических коммуникаций: например, с помощью ботов, аналитики больших данных, платного контента и лидеров мнений в социальных сетях (Wiesenberg, Tench, 2020; Enke, Borchers, 2019; Wiesenberg, Zerfass, Moreno, 2017), но такая практика менее институционализирована и редко регулируется этическими кодексами по сравнению с традиционными СМИ.

С точки зрения этики, стратегическая коммуникация определяется не как непреложное условие управления организацией, но как интеграция перспектив, обеспечивающая адекватность и рефлексивность (Bowen 2016: 3). Этические коммуникации являются частью социальной ткани общества, которая позволяет создавать целостность общественных систем. Этика содействует экономическим и социальным отношениям и реализуется в процессе коммуникации. Так, Макс Вебер (1987) предлагал рассматривать этику в управлении бизнесом как сферу предпринимательского духа, межиндивидуального и группового взаимодействия. Как функция управления бизнесом, этика обеспечивает понимание взаимозависимых отношений между организациями, заинтересованными сторонами и общественностью, которые выходят за рамки частных интересов. Этика в стратегической коммуникации - это рефлексивный подход к управлению, который контекстуализирует обязанности организаций и содействует пониманию своей роли в обществе.

Следует отметить, что стратегические коммуникации понимаются какдолговременное целеполагание, при этом в стратегическом коммуницировании существует фактор неопределенности, связанный сдинамикой развития общественных и коммуникационных систем. Но фактор неопределенности не есть фактор фатальной ограниченности стратегического коммуницирования, напротив - фактор неопределенности побуждает ктактическим решениям, учитывающим непрогнозируемые ситуации и созданию условий для применения тактик для реализации стратегических целей. Эта преемственность, в частности, предполагает этическую соразмерность в деятельности сторон, включенных в стратегические коммуникации. Этика не может быть директивным фактором коммуницирования, но она не только может, но и должна обеспечивать саму возможность действия в условиях коммуницирования.

Существует ли этическая сторона стратегических коммуникаций? Одни исследователи считают, что этика стратегических коммуникаций требует строгих стандартов профессиональные стандарты часто используются как этическая основа профессии. Другие не согласны с такой позицией, поскольку не существует согласованных правил игры между организациями. Р. Пирсон (1989) утверждал, что моральный долг организаций - вести диалог. Впоследствии Дж. Грунинг (2001) включил тезис Р. Пирсона в свою теорию этики коммуникаций, отмечая симметрию как способ выполнения этого обязательства. Вспомним двустороннюю симметричную модель Дж. Грунига (2006), основанную на диалоге и понимании. Ключевым компонентом этой модели стала этика (здесь, в отличие от ассиметричной модели, обе стороны открыты для согласованных изменений). Используя симметричный подход к установлению диалога, можно добиться более этичной, инклюзивной политики в управлении.

Дальнейшее рассмотрение этики в стратегических коммуникациях, предложенное исследователями, заключается в том, что этика должна стать самостоятельным элементом стратегических коммуникаций. Ш. Боуэн (2016) рассматривала этику как нормативный и описательный принцип коммуникации, предложив теоретическую нормативную модель и утверждая, 
что этическая парадигма коммуникационных отношений основана на моральной философии. Другие ученые придерживались ограниченной концепции этического убеждения, принципиально отличного от манипулирования. Роль этики в стратегических коммуникациях также заключается в содействии изменению, развитию гражданского дискурса, раскрытию правды и коллективного управления рисками, разрешению конфликтов или кризисов. Следовательно, стратегические коммуникации должны осуществляться с этической прямотой и рефлексивностью.

\section{Выводы}

Соотношение стратегических коммуникаций и этики поставлено в повестку дня самим ходом развития медиатизированного общества. Этика в стратегических коммуникациях способствует гармонизации отношений, доверию, соблюдению обязанностей перед заинтересованными сторонами, включает инициирование диалога и обмена идеями, предлагает заинтересованным сторонам возможность продвигать согласованные нормы и принципы. Используя симметричный подход к установлению диалога, можно добиться более этичной, инклюзивной политики в управлении организацией. Конечно, этика не претендует на безусловный директивный и регуляторный характер, обладающий единообразным подходом к стратегическим коммуникациям, но абстрагироваться от этической компоненты стратегических коммуникаций в современных условиях значит ставить под сомнение саму возможность достижения согласованных, принимаемых обществом целей.

\section{Библиография}

Вартанова Е.Л. О концептуальных основаниях теории медиа // МедиаАльманах. 2019. № 3. C. 8-17. DOI: 10.30547/mediaalmanah.3.2019.816

Горохов В.М. Репозиционирование СМИ в медиатизированном обществе // МедиаАльманах. 2018. № 5. C. 14-23. DOI: 10.30547/mediaalmanah.5.2018.1423

Горохов В.М., Гринберг Т.Э. Связи с общественностью: векторы развития в медиатизированном обществе // Медиаскоп. 2018. Вып. 4. Режим доступа: http://www.mediascope. ru/2507 DOI: 10.30547/mediascope.4.2018.7

Горохов В.М., Шилина М.Г. Генезис и социальная сущность связей с общественностью: актуальные реалии в условиях транзитивности // Медиаскоп. 2019. Вып. 4. Режим доступа: http://www.mediascope.ru/2590 DOI: 10.30547/mediascope.4.2019.5

Старых Н.В. Стратегические коммуникации: базовые принципы проектирования // Вестн. Моск. ун-та. Сер. 10: Журналистика. 2013. № 2. С. 5-26.

Шилина М.Г., Вартанов С.А. Доверие как категория теории коммуникации в парадигме цифровой экономики: к постановке научной проблемы // МедиаАльманах. 2019. № 1. C. 20-38. DOI: 10.30547/mediaalmanah.1.2019.2038

Bentele G., Nothaft H. (2010) Strategic Communication and the Public Sphere from a European Perspective. International Journal of Strategic Communication 4 (2): 93-116. DOI: $10.1080 / 15531181003701954$

Bowen S. (2004) Expansion of Ethics as the Tenth Generic Principle of Public Relations Excellence: A Kantian Theory and Model for Managing Ethical Issues. Journal of Public Relations Research 16 (1): 65-92. DOI:10.1207/s1532754xjprr1601_3 
Bowen S. (2005) A Practical Model for Ethical Decision Making in Issues Management and Public Relations. Journal of Public Relations Research 17 (3): 191-216. DOI: 10.1207/ s1532754xjprr1703_1

Bowen, S. (2006) Autonomy in Communication: Inclusion in Strategic Management and Ethical Decision-Making, a Comparative Case Analysis. Journal of Communication Management 10 (4): 330-352. DOI: 10.1108/13632540610714791

Bowen S. (2016) Clarifying Ethics Terms in Public Relations from A to V, Authenticity to Virtue. Public Relations Review 42 (4): 564-572. DOI:10.1016/j.pubrev.2016.03.012

Enke N., Borchers N. (2019). Social Media Influencers in Strategic Communication: A Conceptual Framework of Strategic Social Media Influencer Communication. International Journal of Strategic Communication 13 (4): 261-277. DOI: 10.1080/1553118X.2019.1620234

Grunig J. (2006) Furnishing the Edifice: Ongoing Research on Public Relations as a Strategic Management Function. Journal of Public Relations Research 18: 151-176. DOI: 10.1207/ s1532754xjprr1802_5

Grunig J. (2001) Two-way symmetrical public relations: Past, present and future. Handbook of public relations. Thousand Oaks, CA:Sage

Hallahan K., Holtzhausen D., van Ruler B., Vercic D. (2007) Defining Strategic Communication. International Journal of Strategic Communication I (1): 3-35. DOI: 10.1080/15531180701285244

Hepp A. (2020). Deep Mediatization. London: Routledge.

Holtzhausen D., Zerfass A. (2015) Strategic Communication: Opportunities and Challenges of the Research Area. The Routledge Handbook Afstrategic Communiction. London: Routledge.

Knoblauch H. (2020) The Communicative Construction of Reality. London: Routledge.

Pearson R. (1989) Beyond Ethical Relativism in Public Relations: Coorientation, Rules and the Idea of Communication Symmetry. Public Relations Research Annual 1: 67-86. DOI: 10.1207/s1532754xjprr0101-4_3

Weber M. (1987) The Protestant Ethic and "The Spirit of Capitalism". London: Routledge.

Wiesenberg M., Tench R. (2020) Deep Strategic Mediatization: Organizational Leaders' Knowledge and Usage of Social Bots in an Era of Disinformation. International Journal of Information Management 51: 1-9. DOI: 10.1016/j.ijinfomgt.2019.102042

Wiesenberg M., Zerfass A., Moreno A. (2017) Big Data and Automation in Strategic Communication. International Journal of Strategic Communication 11 (2): 95-114. DOI: 10.1080/1553118X.2017.1285770

Zerfass A., Verhoeven P., Moreno A., Tench R. et al. (2020). European Communication Monitor 2020. Ethical Challenges, Gender Issues, Cyber Security, and Competence Gaps in Strategic Communication. Results of a Survey in 44 Countries. Brussels. 